Walker, N. \& Wiltshire, G. H. (1953). J. gen. Microbiol. 8, 273-276.

\title{
The Breakdown of Naphthalene by a Soil Bacterium
}

\author{
By N. WALKER AND G. H. WILTSHIRE \\ Rothamsted Experimental Station, Harpenden, Hertfordshire
}

SUMMARY: A Gram-negative motile bacterium isolated from soil can grow with naphthalene as sole carbon source and produces from it D-trans-1:2-dihydro-1:2dihydroxynaphthalene and salicylic acid.

The decomposition of naphthalene in soil was studied by Tattersfield (1928) in connexion with its use as a soil insecticide. The disappearance of naphthalene from soil was shown to be due to bacterial action and was prevented by sterilizing the soil. Several strains of bacteria which could use naphthalene as a source of carbon were isolated from naphthalene-treated soils by Gray \& Thornton (1928). At about the same time Tausson (1927) found three kinds of bacteria able to metabolize naphthalene in soils from the Black Sea oilfields. These bacteria would not grow on 1- or 2-naphthol, phthalic acid, catechol, hydroquinone, resorcinol, pyrogallol or phloroglucinol. It was concluded that none of these compounds was an intermediate in the breakdown of naphthalene and that probably both rings were split simultaneously. On the other hand, other bacteria which could grow on phenanthrene (but not on naphthalene) could use catechol, salicylic acid and saligenin but not resorcinol, phloroglucinol, pyrogallol or phthalic acid (Tausson, 1928). The oxidation of phenanthrene was supposed to proceed via 2-hydroxybenzyl alcohol, 2-hydroxybenzaldehyde, salicylic acid and catechol. Jacobs (1931) reported a positive fluorescein test for phthalic acid in a pure culture of a naphthalenedecomposing bacterium. In a note, Strawinski \& Stone (1943) claimed to have found 'ortho-salicylic acid' in the acid ether extract from a culture of Pseudomonas aeruginosa grown on naphthalene. They gave no experimental details and we have been unable to trace any subsequent publication.

The simultaneous adaptation technique of Stanier (1947) was used in the present work as a means of deciding whether various compounds were intermediates in the bacterial metabolism of naphthalene.

\section{METHODS}

The naphthalene-decomposing organism was isolated from Rothamsted allotment soil by enrichment culture in a modified Lees \& Quastel (1944) percolator, followed by plating on mineral agar with naphthalene as the only other carbon source. The percolator was charged with $20 \mathrm{~g}$. of $3 \mathrm{~mm}$. soil crumbs mixed with $\mathbf{0} \cdot \mathbf{2 5} \mathrm{g}$. sublimed naphthalene and perfused with tap water for 1 week.

Media. Tausson's (1927) medium was used with or without the addition of agar. It consists of two solutions which were sterilized separately and mixed aseptically in the proportion of 4 of $(a)$ to 1 of $(b)$. Solution $(a)$ is: $\mathrm{Ca}\left(\mathrm{NO}_{3}\right)_{2}$, $1 \mathrm{~g}$.; $\mathrm{KNO}_{3}, 0 \cdot 25 \mathrm{~g}$.; $\mathrm{MgSO}_{4} .7 \mathrm{H}_{2} \mathrm{O}, 0 \cdot 25 \mathrm{~g}$.; $\mathrm{Fe}_{2}\left(\mathrm{SO}_{4}\right)_{3}, 0 \cdot 005 \mathrm{~g}$.; distilled water, 
$800 \mathrm{ml}$. Solution $(b)$ is: $\mathrm{KH}_{2} \mathrm{PO}_{4}, 0.5 \mathrm{~g}$.; $\mathrm{K}_{2} \mathrm{HPO}_{4}, 0.5 \mathrm{~g}$; d distilled water, $200 \mathrm{ml}$.

Culture conditions. Plates of Tausson's medium solidified with Difco standardized agar $(2 \%, \mathrm{w} / \mathrm{v})$ were inoculated and inverted over crystals of freshly sublimed naphthalene contained in the lid. Cultures in liquid media were grown in 11 . Roux bottles containing $125 \mathrm{ml}$. or in 21 . conical flasks containing $500 \mathrm{ml}$. About $\mathbf{0 \cdot 1} \mathrm{g}$. sterile naphthalene was added aseptically to each bottle after autoclaving. All cultures were incubated at $25^{\circ}$.

Naphthalene diols. DL-trans-1:2-dihydro-1:2-dihydroxynaphthalene and the L-isomer were isolated from the urine of rabbits and rats, respectively, which had been given naphthalene. A pure specimen of L-diol was a gift from Prof. L. Young. The diols were estimated as 1-naphthol by the method of Boyland \& Wiltshire (1953).

Manometric method. Oxygen uptake was measured in Warburg manometers. The organisms for these experiments were grown on agar plates for 4-5 days, washed twice with $0.02 \mathrm{M}$-phosphate $(\mathrm{pH} 7 \cdot 0)$ and resuspended in the same buffer.

\section{RESULTS \\ Description of organism}

The strain used was an aerobic motile Gram-negative rod which did not liquefy nutrient gelatin. On mineral salts agar+naphthalene the smooth circular colonies (6-8 mm. diam.) became coloured yellow and later brown. These properties do not distinguish it from the Bacillus naphthalinicum nonliquefaciens of Tausson (1928).

\section{Detection and isolation of salicylic acid}

Liquid cultures after 4-6 days showed a marked violet colour on adding dilute ferric chloride solution. Paper chromatography of these cultures by the method of Bray, Thorpe \& White (1950) revealed a spot with the same $\boldsymbol{R}_{f}$ value as salicyclic acid, $23 \mathrm{mg}$. of this compound were isolated from about 21 . of acidified culture by extraction into ether. The ether extract was washed with water and with $2 \%(\mathrm{w} / \mathrm{v})$ sodium bicarbonate solution. The aqueous layer was acidified with dilute hydrochloric acid, extracted with fresh ether, the ethereal layer separated, washed with water, dried over sodium sulphate, filtered and evaporated to dryness. The residue was crystallized from water and sublimed over a boiling water-bath; colourless needles were obtained, m.p. $156^{\circ}$; mixed m.p. with authentic salicylic acid $156-157^{\circ}$. On heating with a drop of methanol and sulphuric acid, the odour of methyl salicylate was detected.

\section{Detection and isolation of naphthalene diol}

Liquid cultures grown for about 2 days contained a substance which yielded 1-naphthol after treatment with $\mathrm{N}$-hydrochloric acid for $15 \mathrm{~min}$. at $100^{\circ}$. Practically no free naphthol was found at this stage of growth. The culture was neutralized with sodium bicarbonate, heated to $70^{\circ}$ and filtered. The diol in 21 . culture filtrate was adsorbed by stirring with $4 \mathrm{~g}$. animal charcoal, the charcoal separated and eluted 3 or 4 times with hot ethanol. The combined 
eluates were concentrated to dryness, under reduced pressure, below $40^{\circ}$. The residue was extracted with boiling benzene and the benzene solution evaporated to dryness. The residue (12 mg.) recrystallized from hot benzene yielded $9.5 \mathrm{mg}$. colourless needles, m.p. $125^{\circ}$. (Found: C, 73.6; H, 5.9; calc. for $\mathrm{C}_{10} \mathrm{H}_{10} \mathrm{O}_{2}$; C, $74 \cdot 1 ; \mathbf{H}, 6 \cdot 2$.) Further recrystallization raised the m.p. to $127^{\circ}$ (Kofler block). The spectrum of this substance in solution in $95 \%(\mathrm{v} / \mathrm{v})$ ethanol showed an absorption maximum at $263-4 \mathrm{~m} \mu$, ; authentic pL-trans-1:2-dihydro-1:2dihydroxynaphthalene had a maximum at $264 \mathrm{~m} \mu$.; the spectra of naphthalene
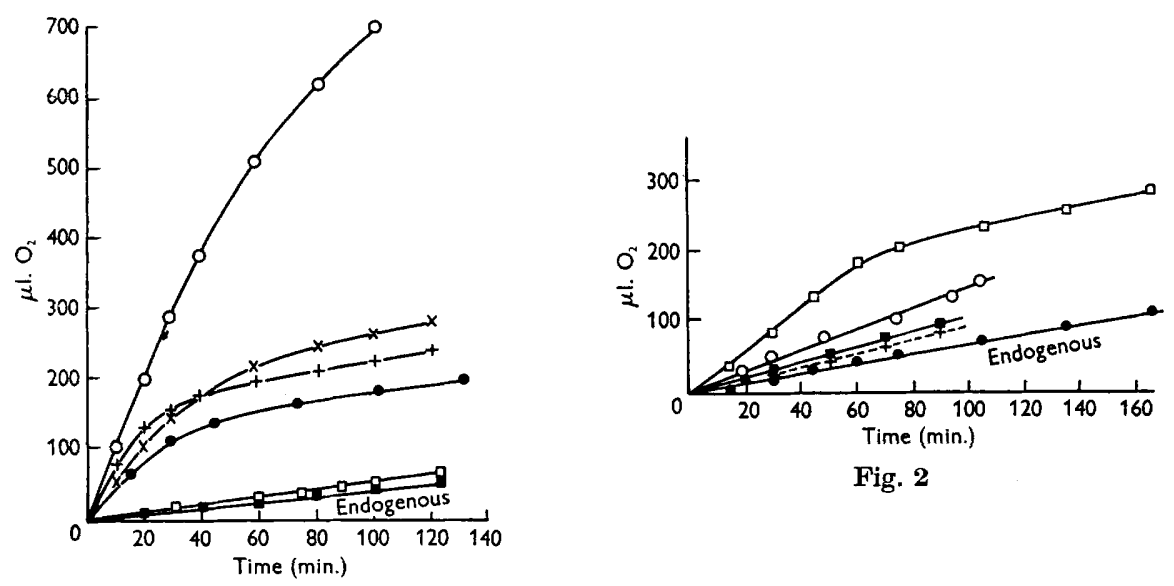

Fig. 2

Fig. 1

Fig. 1. Rate of oxygen uptake of washed cells grown on naphthalene. In presence of: naphthalene $(8 \cdot 3 \mu$ mole $/ 3 \mathrm{ml}$ ) $(\mathrm{O}-\mathrm{O})$, salicylate $(2.5 \mu \mathrm{mole} / 3 \mathrm{ml}$.) $(\times-\times)$, DL-'diol'

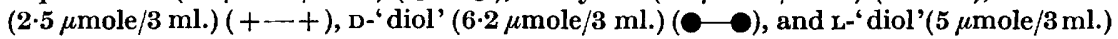
( $\square-\square)$, as substrates.

Fig. 2. Rate of oxygen uptake of washed cells grown on naphthalene. In presence of: catechol (5 $\mu$ mole $/ 3 \mathrm{ml}$.) ( $\square-\square)$, coumarin (2.5 $\mu \mathrm{mole} / 3 \mathrm{ml}$.) ( $\square-\square), 1: 2$-dihydroxynaphthalene $(5 \mu \mathrm{mole} / 3 \mathrm{ml}).(+\cdots+)$, and $\beta$-naphthoquinone $(1 \cdot 3 \mu \mathrm{mole} / 3 \mathrm{ml}$. $(\mathrm{O}-\mathrm{O})$ as substrates.

and of 1- and 2-naphthol are different. The specific rotation $(\alpha)_{D}^{22}+161^{\circ}$ $\left(c=0.3712 \%\right.$ in ethanol) compares with $+159^{\circ}(c=1 \%$ in ethanol) found by Booth \& Boyland (1949) for D-trans-1:2-dihydro-1:2-dihydroxynaphthalene from urine of rabbits treated with naphthalene. Unfortunately no specimen of this compound was available for comparison, but mixtures of the bacterial product with L-trans-1:2-dihydro-1:2-dihydroxynaphthalene from rat urine (m.p. $127^{\circ}$ ) melted at various temperatures between 99 and $120^{\circ}$.

\section{Manometric experiments}

The bacteria grown on naphthalene were found to be simultaneously adapted to oxidize salicylic acid, catechol, the D-trans-diol and the DL-trans-diol, but not the L-trans-diol, $\alpha$-naphthoquinone, 3-hydroxybenzoic acid, trans-coumaric acid or 1-naphthol. There were small oxygen uptakes with coumarin, $\beta$-naphthoquinone and 1:2-dihydroxynaphthalene. These results are illustrated in Figs. 1 and 2. 


\section{DISCUSSION}

In his work on the decomposition of phenanthrene Tausson $(1927,1928)$ decided that 2-hydroxybenzyl alcohol, salicylic acid and catechol were intermediates because they could serve as sole sources of carbon for growth and were not toxic; no such intermediates were established in the case of naphthalene. A pure culture of bacteria growing in a simple medium with naphthalene as sole carbon source presents a favourable system for a study of the breakdown of this hydrocarbon. We found that our organism did not grow on 1-naphthol, 2-naphthol or phthalic acid, but did grow on salicylic acid. When grown on naphthalene, washed cells showed an immediate oxygen uptake with the D-trans-diol, salicylic acid or catechol; the first two of these compounds were also isolated from growing cultures. The formation of catechol from salicylic acid by certain pseudomonads is known to occur (Walker \& Evans, 1952).

The naphthalene diols have been known hitherto only as products of naphthalene metabolism in mammals where both $\mathrm{D}$ - and $\mathrm{L}$-isomers are formed (Young, 1947; Booth \& Boyland, 1949). Evidently they may also be produced at an early stage of oxidation of naphthalene by bacterial cells.

We are grateful to Prof. L. Young for the gift of L-trans-diol, to Prof. W. C. Evans for gifts of coumarin, trans-coumaric acid and $\alpha$ - and $\beta$-naphthoquinones, and to Dr D. E. Hathaway for determining the specific rotation of the diol.

\section{REFERENCES}

Booth, J. \& Boyland, E. (1949). Metabolism of polycyclic compounds. 5. Formation of $1: 2$-dihydroxy-1:2-dihydronaphthalenes. Biochem. J. 44, 361 .

Boyland, E. \& Wiltshire, G. H. (1953). Metabolism of naphthalene by liver slices. Biochem. J. 53, 424.

Bray, H. G., Thonpe, W. V. \& White, K. (1950). The fate of certain organic acids and amides in the rabbit. 10. The application of paper chromatography to metabolic studies of hydroxybenzoic acids and amides. Biochem. J. 46, 271.

Gray, P. H. H. \& Thornton, H. G. (1928). Soil bacteria that decompose certain aromatic compounds. Zbl. Bakt. (2 Abt.), 73, 74.

JACOBS, S. E. (1931). The influence of antiseptics on the bacterial and protozoan population of greenhouse soils. Part I. Naphthalene. Ann. appl. Biol. 18, 98.

LeEs, H. \& Quastel, J. H. (1944). A new technique for the study of soil sterilization. Chem. \& Ind. (Rev.) p. 238.

Stanier, R. Y. (1947). Simultaneous adaptation: A new technique for the study of metabolic pathways. J. Bact. 54, 339 .

Strawinski, R. J. \& Stone, R. W. (1943). Conditions governing the oxidation of naphthalene and the chemical analysis of its products. J. Bact. 45, 16.

Tattersfield, F. (1928). The decomposition of naphthalene in the soil and the effect upon its insecticidal action. Ann. appl. Biol. 15, 57.

Tausson, W. O. (1927). Naphthalin als Kohlenstoffquelle für Bakterien. Planta, $4,214$.

Tausson, W. O. (1928). Die Oxydation des Phenanthrens durch Bakterien. Planta, $5,239$.

Walker, N. \& Evans, W. C. (1952). Pathways in the metabolism of the monohydroxybenzoic acids by soil bacteria. Biochem. J. 52, xxiii.

Young, L. (1947). The metabolic conversion of naphthalene to 1:2-dihydroxynaphthalene-1:2-diol. Biochem. J. 41, 417.

(Received 22 August 1952) 